Mehmet Akif Ersoy Üniversitesi Fen Bilimleri Enstitüsü Dergisi 10(1): 84-89 (2019)

The Journal of Graduate School of Natural and Applied Sciences of Mehmet Akif Ersoy University 10(1): $84-89$ (2019)

Araştırma Makalesi / Research Paper

\title{
Ak Dut Ağacı Dal ve Gövde Odununun Anatomik Açıdan Karşılaştırmalı Analizi
}

\author{
Göksu ŞiRIN (1) ${ }^{\text {* }}$, Gökhan GÜNDÜZ iD2 \\ ${ }^{1}$ Gaziosmanpaşa Üniversitesi, Almus Meslek Yüksekokulu, Tokat \\ ${ }^{2}$ Bartın Üniversitesi, Orman Fakültesi, Bartın \\ Geliş Tarihi (Received): 15.05.2019, Kabul Tarihi (Accepted): 15.07.2019 \\ $\square$ Sorumlu Yazar (Corresponding author*): goksu.sirin@gop.edu.tr \\ (C) +903562521616 且 +903564113033
}

ÖZ

Ağaçta dal odunu toplam odun hacminin yaklaşık \%30'unu oluşturur. Endüstriyel açıdan dal odunu çeşitli kullanım alanları için iyi bir alternatif kaynak olabilir. Bu durumda özelliklerinin bilinmesi gerekmektedir. Dal odunu ve gövde odunu anatomik özellikleri açısından farklılıklar göstermektedir. Bu çalışmada Ak dut ağacı gövde ve dal odununun bazı anatomik özellikleri karşılaştırılmıştır. İki odun türü için yapılan ölçümlerde istatistiksel analiz sonuçlarına göre trahe sayısı, özışını hücresi özellikleri ve lif hücresi özelliklerinde fark anlamlı bulunmuştur. Ölçümlere göre gövde odununda birim alana düşen trahe sayısı ilkbahar odununda \%41, yaz odununda \%69 fazladır. Yine gövde odununda özışını yüksekliği \%34 daha fazla bulunmuştur. Lifler dal öz odununda \%11 ve dal diri odununda \%20 kısa olarak belirlenmiştir. Lif genişliği dal öz odununda \%18, diri odunda \%20 ve lümen genişliği öz odunda \%29, diri odunda \%18 fazladır. Dal öz ve diri odununda lif çeper kalınlığı sırasıyla \%3 ve \%6 fazla bulunmuştur. Çalışmanın sonuçları, gövde ve dal odununun hücresel yapısındaki farklılıkların odun işleme ve kullanımında dikkate alınması gereken bir faktör olduğunu göstermektedir.

Anahtar Kelimeler: Morus alba, gövde odunu, dal odunu, odun anatomisi

\section{Comparative Analysis for Anatomical Differences between Branch and Trunk in White Mulberry Wood}

\begin{abstract}
In the tree, branch wood constitutes approximately $30 \%$ of total wood volume. From an industrial point of view, branch wood can be a good alternative for a variety of applications. In this case the properties need to be known. Branch wood and stem wood differ in anatomical characteristics. In this study, some anatomical features of White mulberry tree trunk and branch wood were compared. According to the results of statistical analysis in the measurements made for the two wood types, the difference in number of vessel, ray properties and fiber cell properties were significant. According to the measurements, vessel frequency in the stem early wood is $4 \%$ and stem late wood is $69 \%$ higher. Again, the ray height of the trunk wood was $34 \%$ more. The fibers were determined to be $11 \%$ short in branch heartwood and $20 \%$ short in branch sapwood. Fibre width in branch heartwood and sapwood is $18 \%$ and $20 \%$ and lumen width in branch heartwood and sapwood is $29 \%$ and $18 \%$ higher. Fiber wall thickness was found to be $3 \%$ and $6 \%$ more in branch heartwood and sapwood respectively. The results of the study show that the differences in cellular structure of trunk and branch wood is a factor to be considered in wood processing and use.
\end{abstract}

Keywords: Morus alba, stem wood, branch wood, wood anatomy 


\section{GíRiş}

Ağaçların anatomik, kimyasal, fiziksel ve mekanik özellikleri türler arsında farklılıklar gösterir. Ağaç heterojen özelliktedir ve gövde, dal, kökün oluşturduğu farklı yapılardaki odunlardan meydana gelir. Eğer bir ağaç tam olarak tanımlanmak istenirse yapıları farklı olan bu üç odun türü hakkında bilgi verilmelidir. Ağaç malzeme kullanım alanı çok fazla olan doğal bir hammaddedir. $\mathrm{Bu}$ nedenle ağaç malzemenin uygun şekilde kullanılması için özelliklerinin tam tanımlanması önemlidir. Ağaçların anatomik özellikleri onların kullanım alanlarını belirler (Englerth, 1966; McElwee ve ark., 1970; Vurdu, 1977). Kullanım alanları için ağacın daha ziyade gövde odunu değerlendirildiğinden çalışmalar gövde odunu üzerinde yoğunlaşmıştır. Dünyada artan nüfus ve yeni uygulama alanları nedeniyle orman endüstrisinde oduna olan talebin artması orman kaynakları üzerinde önemli bir baskı oluşturmaktadır. Gelecekteki talebi karşılamak ve odun kıtlığını gidermek için, orman endüstrisindeki yeni veya alternatif kaynakların hammadde bileşenleri olarak kullanmasına yönelik çalışmalar yapılmaktadır (Ashori, 2006; Çöpür ve ark., 2007; Samariha ve ark., 2011). Ağaç malzemenin değerli bir materyal olması nedeniyle bir ağaçta tüm kısımların kullanımının en üst düzeye çıkarılması noktasında, ağaç endüstrisinde dal odunu ve kök odunu giderek daha fazla önem kazanmaktadır (Haygreen ve Bowyer, 1996; Yaman, 2014). Dal odunu toplam odun hacminin \%25 - \%32'sini (Hilton, 2001) oluşturur ve hakkında yeterli araştırma yapılmamış ancak uygulamalar için önemli potansiyele sahip ikincil bir kaynaktır (Gurau ve ark., 2008). Dal odunu ve gövde odunu araştırmalarında literatürde ilk olarak karşılaşılan bilgi kural olarak dal odununun gövde odununa göre daha yoğun, ağır, sert ve kırılgan olduğudur (Kurtoğlu, 1986). Yıllık halka ve hücre yapılarının farklı olması nedeniyle dal odununun özgül ağırlığı gövde odunundan daha fazla bulunmaktadır. Dal odununun hücre çeperleri daha kalın, destekleyici hücre dokusu katılım oranı daha fazladır (Kurtoğlu,1984).

Bu çalışmada Ak dut ağacının bazı anatomik özellikleri gövde ve dal odunu için incelenmiştir. Ak dut, Moraceae familyası ve bu familyanın Morus $\mathrm{L}$. cinsine dahil ağaçlardandır. Ağacın anavatanı Çin olmakla beraber (Gökmen, 1973) Türkiye`de özellikle Orta ve Doğu Anadolu'da yayılış göstermektedir (Anonim, 2002). Dut farklı iklimlerde ve topraklarda yetişme kabiliyetine sahiptir. Kayalık, kuru-fakir topraklarda dahi yetişebilir. Tuzlu suya karşı dayanımı da oldukça fazladır (Yücel ve ark., 1995). Dut ağaçlarının çoğu anavatanlarından götürülüp adaptasyonu yapılarak yetiştirildiği bölgelerin tabii bitkisi haline gelmiştir (Machii ve ark., 2001). Moraceae familyası ağaçlarının daha çok meyvesi ve yaprakları incelenmiş olup odun özellikleri hakkında sınırlı sayıda çalışma bulunmaktadır (Gündüz ve ark., 2009; Karami ve ark. 2010; Melo Junior ve ark. 2018; Palhares ve ark., 2007) Gündüz ve ark. (2009) çalışmalarında Ak dut ağacının anatomik, kimyasal, fiziksel ve mekanik özelliklerini araştırmış ve bazı anatomik özellikler (trahe teğet ve radyal çapları, özışını özellikleri) hakkında sayısal bilgiler vermişlerdir.

\section{MATERYAL VE YÖNTEM}

\section{Materyal}

İncelenen ağaç Ankara ili Beypazarı ilçesi İnözü mevkiinde $1000 \mathrm{~m}$ rakımda kuzeybatı bakısından alınmıştır. Ak dut (Morus alba L.) ağacının anatomik özelliklerinin belirlenmesi için örnekler ağacın $1.30 \mathrm{~m}$ yüksekliğindeki gövde bölümü ile bir dalından alınmıştır.

\section{Yöntem}

Ağaçların heterojen yapıları sebebiyle değişik noktalarında farklı özellikler gösterdiği bilinmektedir. Bu çalışmada parçalara ayrılan gövde ve dal odununda örnekler farklı bölgelerden alınmıştır. İncelemeler için belirlenen gövde ve dal numuneleri $2 \times 2 \times 2 \mathrm{~cm}$ boyuta getirildikten sonra önce destile su içerisinde kabın dibine çökünceye kadar kaynatılmıştır ve daha sonra FAA (Formalin-Asetic-Alkol) çözeltisinde 20 gün bekletilmiştir (Berlyn ve Miksche, 1976). Bu süre sonunda örneklerden Reichert kızaklı mikrotomu ile enine, yıllık halkalara dik (radyal) ve yıllık halkalara teğet yönde kesitler alınmıştır. Alınan kesitlerle hazırlanan preparatların boyama işlemi safranin ya da fast green ile yapılmış, rengin sabitlenmesi için ksilol, yapıştırıcı olarak Kanada Balsam kullanılmıştır. Anatomik çalışmalarda, istatistiki olarak sağlam sonuçlar elde etmek için sayım ve ölçümlerde S. Carlquist 25, IAWA Committee ise 50 yi esas almaktadır (Carlquist, 1986). Ölçümler ilkbahar odunu ve yaz odunu için ayrı ayrı yapılmıştır. $1 \mathrm{~mm}^{2}$ lik alanlardaki trahe sayıları, trahelerin radyal ve teğet yöndeki çapları, $1 \mathrm{~mm}$ içindeki özışınlarının sayısı, yüksekliği ve genişliği ölçülmüştür. Ölçümler X10 objektifte oküler mikrometresi kullanılarak yapılmıştır.

Lif ve trahe hücreleri özelliklerinin belirlenmesinde numuneler diri ve öz odun için ayrı olmak üzere alınmıştır. Klorit maserasyon yöntemi ile hücreler serbest hale getirilmiştir. Serbest hale gelen lif ve trahe hücreleri gliserin ile karıştırılmış ve safranin ile kırmızıya boyandıktan sonra lam ve lamel arasına alınarak preparatlar hazırlanmıştır. Hazırlanan preparatlarda trahe perforasyon tipi, lif uzunluğu, lif genişliği, lif lümen genişliği ve lif çift çeper kalınlığı ölçümleri yapılmıştır. Mikroskopta oküler mikrometresi ile lif hücresi uzunluğu ölçümleri X10, lif genişliği, lümen genişliği ve çeper kalınlığı ölçümleri X40 objektif kullanılarak yapılmıştır. 


\section{BULGULAR ve TARTIŞMA}

Ağaçta halkalı trahe düzeni vardır ve yıllık halka sınırı belirgindir. Illkbahar odunu traheleri çoğunlukla oval şekilde, yaz odunu traheleri çoğunlukla köşeli yapıda olup gruplar halinde dizilmiştir. Sınır paranşimleri gö- rülmektedir. Gövde ve dal odunu trahe hücrelerinde tül oluşumu gözlenmiştir. Perforasyon tablası basit tiptedir. Şekil 1'de enine kesitte trahelerin görünüşü, Şekil 2'de ilkbahar ve yaz odunu traheleri ve Şekil 3'de yıllık halka sınırı ve özışınlarının yapısı görülmektedir.
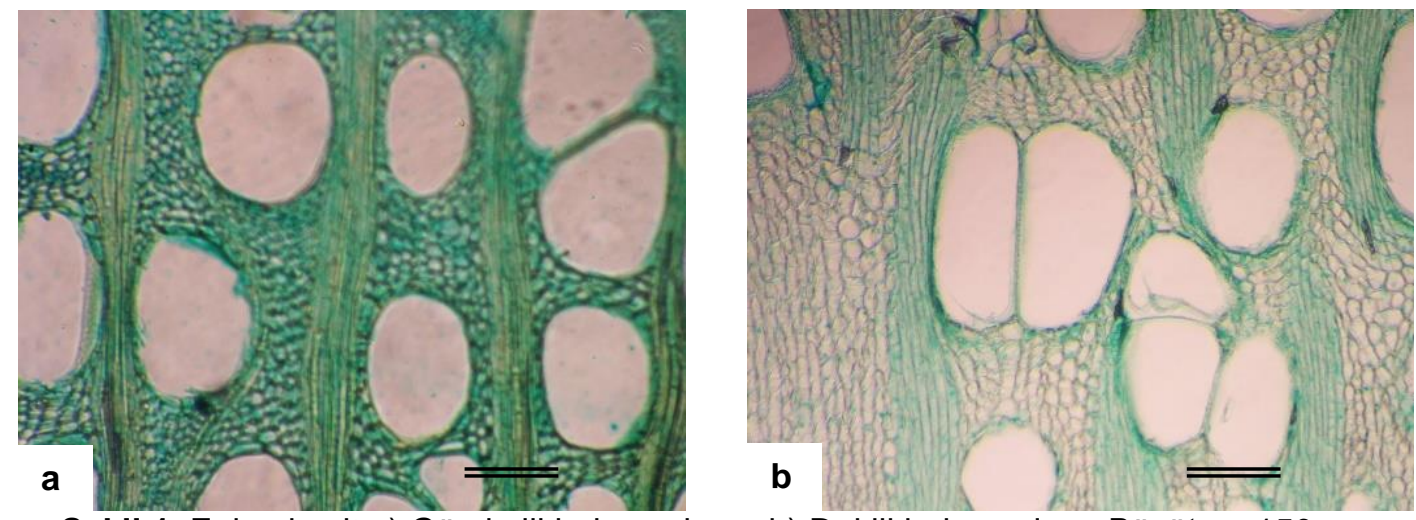

Şekil 1. Enine kesit a) Gövde ilkbahar odunu, b)

Dal ilkbahar odunu Büyütme:150 $\mu \mathrm{m}$

a

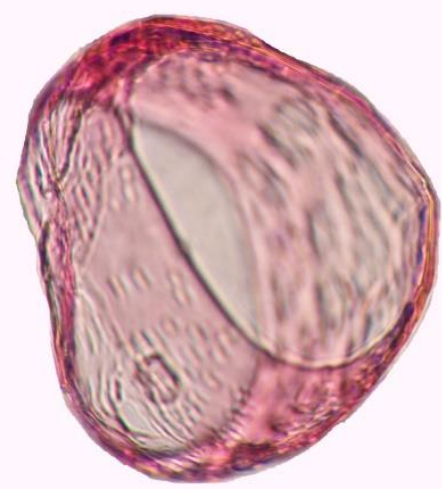

b

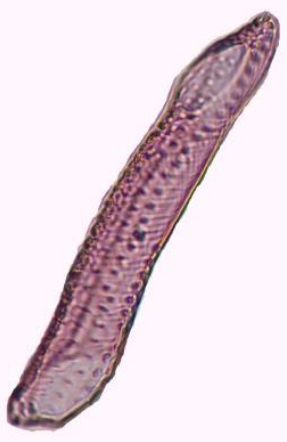

Şekil 2. a) İlkbahar odunu trahesinde perforasyon tablasının görünüşü, b) Yaz odunu trahesinde perforasyon tablasının görünüşü Büyütme: $100 \mu \mathrm{m}$
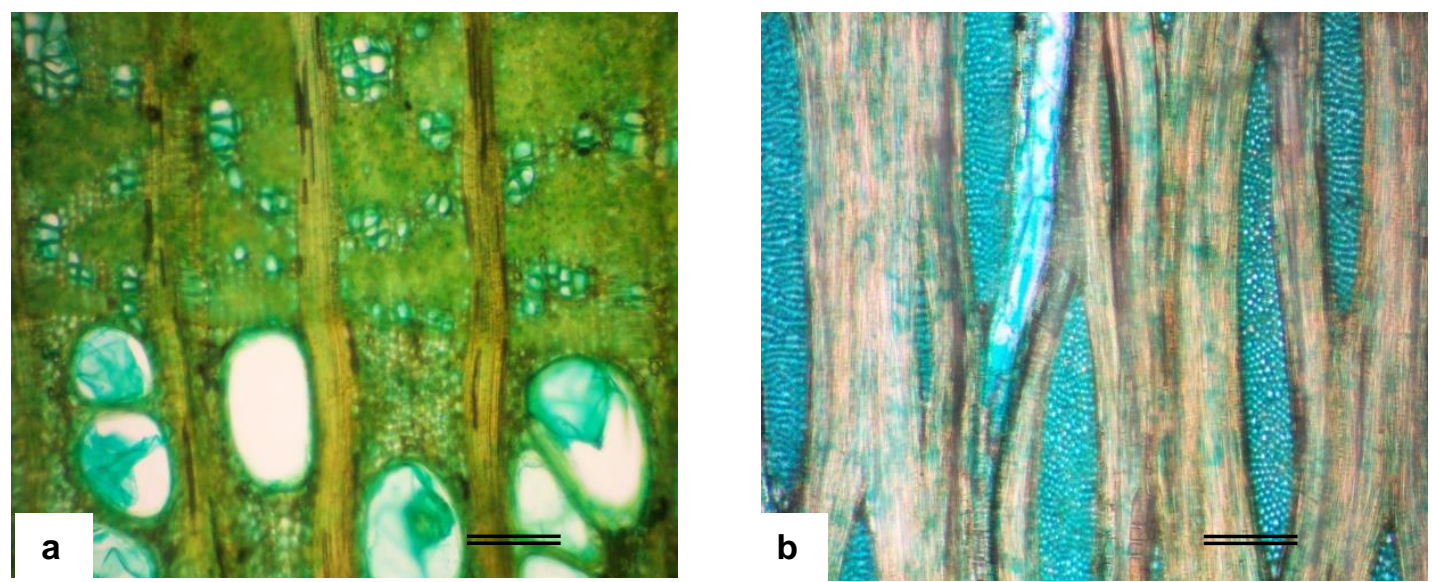

Şekil 3. a) Enine kesit gövde odununda yıllık halka sınırı ve tül oluşumu Büyütme:150 $\mu \mathrm{m}$, b) Teğet kesit dal odunu Büyütme:70 $\mu \mathrm{m}$ 
Ak dut (Morus alba L.) ağacı gövde ve dal odunu üzerinde yapılan anatomik ölçümlere ait temel istatistikler
Tablo 1'de özetlenmiştir.

Tablo 1. Ak dut (Morus alba L.) ağacı gövde ve dal odununda ölçülen özellikler

\begin{tabular}{|c|c|c|c|c|}
\hline \multirow[b]{2}{*}{ Özellik } & \multicolumn{2}{|c|}{ Gövde Odunu } & \multicolumn{2}{|c|}{ Dal Odunu } \\
\hline & Ortalama & Standart Sapma & Ortalama & Standart Sapma \\
\hline İlkbahar odunu trahe teğet çapı $(\mu \mathrm{m})$ & 161.3 & 17.9 & $166.6^{\mathrm{ns}}$ & 15.7 \\
\hline Yaz odunu trahe teğet çapı $(\mu \mathrm{m})$ & 41.9 & 8.9 & $47.0^{\text {ns }}$ & 16.4 \\
\hline İlkbahar odunu trahe radyal çapı ( $\mu \mathrm{m})$ & 230.3 & 28.3 & $222.1^{\mathrm{ns}}$ & 50.0 \\
\hline Yaz odunu trahe radyal çapı ( $\mu \mathrm{m})$ & 51.4 & 10.3 & $56.4^{\text {ns }}$ & 23.6 \\
\hline İlkbahar odunu trahe sayısı & 13.7 & 1.45 & $9.7^{\star * *}$ & 1.6 \\
\hline Yaz odunu trahe sayısı & 60.7 & 28.5 & $36.0^{*}$ & 10.9 \\
\hline Öz odun lif uzunluğu ( $\mu \mathrm{m})$ & 1123.4 & 59.6 & $1011.4^{* * *}$ & 47.4 \\
\hline Diri odun lif uzunluğu ( $\mu \mathrm{m})$ & 1221.6 & 19.9 & $1013.8^{* * *}$ & 19.9 \\
\hline Öz odun lif genişliği ( $\mu \mathrm{m})$ & 15.6 & 1.7 & $19.1^{* * *}$ & 1.0 \\
\hline Diri odun lif genişliği $(\mu \mathrm{m})$ & 14.8 & 0.7 & $18.6^{\star \star \star}$ & 0.7 \\
\hline Öz odun lif lümen genişliği ( $\mu \mathrm{m})$ & 6.7 & 0.3 & $9.5^{\star * *}$ & 0.3 \\
\hline Diri odun lif lümen genişliği $(\mu \mathrm{m})$ & 6.4 & 0.2 & $7.8^{* * *}$ & 0.2 \\
\hline Öz odun lif çift çeper kalınlığı ( $\mu \mathrm{m})$ & 8.9 & 0.2 & $9.2^{* *}$ & 0.1 \\
\hline Diri odun lif çift çeper kalınlığı $(\mu \mathrm{m})$ & 8.4 & 0.2 & $8.9^{* * *}$ & 0.1 \\
\hline Özışını sayısı & 3.7 & 0.2 & $3.2^{*}$ & 0.4 \\
\hline Özışını genişliği ( $\mu \mathrm{m})$ & 76.9 & 5.9 & $73.2^{\text {ns }}$ & 6.3 \\
\hline Özışını yüksekliği ( $\mu \mathrm{m})$ & 596.5 & 100.3 & $446.8^{\pi x}$ & 112.6 \\
\hline
\end{tabular}

Dal odunu ve gövde odunu arasında trahe çapları ve özışını genişliği açısından anlamlı bir farklılık yok iken burada incelenen diğer anatomik özellikler açısından anlamlı farklılıklar tespit edilmiştir.

Gövde odununda birim alana düşen trahe sayısı ilkbahar odununda ortalama 13.7 ve yaz odununda 60.7 olarak belirlenmiştir. Karami ve ark. (2010) çalışmalarında gövde odunu için birim alandaki trahe sayısını ilkbahar odununda ortalama 30, yaz odununda 100'den fazla olarak belirtmiştir. Burada görülen fark yıllık halka genişliğinden kaynaklanabilmektedir (Şanlı, 1977). Enine kesit sonuçlarına göre gövde odununda birim alana düşen trahe sayısı hem ilkbahar hem de yaz odununda dal odunundan daha fazladır. İlkbahar odununda $\% 41$, yaz odununda ise $\% 69$ fark görülmektedir. Dadzie ve ark. (2016) Terminalia superba için yaptıkları çalışmada gövde odununda trahe oranını dal odununa göre fazla bulmuştur. Gövde ilkbahar odununda trahe teğet ve radyal çapları ortalaması sırasıyla $161.3 \mu \mathrm{m}$ ve $230.3 \mu \mathrm{m}$, yaz odunu için ise $41.9 \mu \mathrm{m}$ ve $51.4 \mu \mathrm{m}$ olarak bulunmuştur. Karami ve ark. (2010) gövde ilkbahar odunu trahesi teğet ve radyal çaplarını sırasıyla ortalama $192 \mu \mathrm{m}$ ve $238 \mu \mathrm{m}$, yaz odunu trahelerini ise ortalama $63 \mu \mathrm{m}$ ve $59 \mu \mathrm{m}$ olarak belirlemiştir.

Teğet kesit sonuçlarına göre birim alana düşen özışını sayısı, yüksekliği ve genişliği gövde odununda daha fazla bulunmuştur. Stokke ve Manwiller (1994) Quercus velutina için yaptıkları çalışmada önemli bir fark olmamakla beraber özışını sayısını gövde odununda dal odununa göre daha fazla bulduklarını belirtmektedir. İstatistiksel olarak anlamlı fark bulunan özışını yüksekliği gövde odununda \%34 daha fazladır. Bu çalışmada özışınları için yapılan ölçümlerde gövde odununda özışını sayısı mm'de ortalama 3.7 , dal odunu için ise 3.2 bulunmuştur. Ağaçtaki özışınları mültiseri özelliktedir ve homoselüler yapı göstermektedir. Gövdede yan 
yana en fazla 9 sayıda hücre dalda en fazla 8 sayıda hücre dizilmiştir. Çevre hücreleri bulundurdukları görülmüştür. Bozkurt ve Erdin (1995) çalışmalarında Ak dut ağacı gövde odununda özışını sayısının mm'de 3-5 adet ve 8 hücre kadar genişlikte, Karami ve ark. (2010) ise mm'de 8 adet ve 4-12 hücre kadar genişlikte olduğunu belirtmiştir.

Farklı türler üzerine yapılan çalışmalarda dallarda lif uzunluğunun gövdelere göre daha kısa olduğu sonucu görülmüştür (Bhat ve ark., 1985, Bhat ve ark.,1989; Phelps ve ark., 1982; Samariha ve ark., 2011; Yaman, 2014; Dadzie ve ark., 2016). Karami ve ark. (2010) Morus alba L. ağacında lif uzunluğunu gövde öz ve diri odunu ayrımı yapmadan $1098 \mu \mathrm{m}$ olarak belirtmiştir. Bu çalışmada lif hücreleri gövde öz odununda $1123.4 \mu \mathrm{m}$ ve diri odunda $1221.6 \mu \mathrm{m}$ uzunlukta ölçülmüştür. Lifler dal öz odununda $\% 11$ ve dal diri odununda $\% 20 \mathrm{kısa}$ olarak belirlenmiştir. Aynı zamanda dal odununda lif genişliği öz odunda $\% 18$, diri odunda $\% 20$ ve lümen genişliği öz odunda \%29, diri odunda $\% 18$ fazladır. Kaynaklarda dal odununda yapısal olarak hücre çeper kalınlıklarının daha fazla olduğu (Kurtoğlu,1984) belirtilmiştir. Bu çalışmada istatistiki olarak yine anlamlı fark olmakla birlikte dal öz ve diri odununda lif çeper kalınlığı sırasıyla \%3 ve \%6 fazla bulunmuştur.

\section{SONUÇLAR}

Çalışmanın amacı Ak dut ağacının mikroskobik özelliklerinin gövde ve dal odunundaki farklılıklarının araştırılmasıydı. Ak dut ağacı bazı Moraceae türlerinden homojen özışınları ve belirgin yıllık halka sınırı ile ayrılmaktadır (Gündüz ve ark., 2009).

Bu çalışmada analizlerden elde edilen sonuçlar, gövde ve dal odununda anatomik açıdan istatistiki olarak farklar olduğunu göstermektedir. İlkbahar odunu ve yaz odunu trahe sayısı gövde odununda daha yüksektir. Teğet ve radyal çaplarda önemli bir fark görülmemektedir. Özışınları için yapılan tüm ölçümlerde gövde odunu değerleri yüksek bulunmuştur. Fark özışını yüksekliği için oldukça belirgindir. Dal odununda öz odun ve diri odunun her ikisinde de lif hücrelerinin daha kısa, lif genişliği, lümen genişliği ve çeper kalınlığının daha fazla olduğu görülmüştür.

Ağaçlar için yapılan anatomik çalışmalar daha çok gövde odunu üzerinde yoğunlaşmaktadır. Gövde odunu ve dal odunu, nitel ve nicel özellikler bakımından önemli farklar gösterebilmektedir (Marcati ve ark., 2014). Karşılaştırmalı olarak yapılan analizler alternatif bir odun kaynağı olarak düşünülen dal odununu daha iyi tanımlamakta ve kullanım alanları hakkında yardımcı olabilmektedir. Çalışmada elde edilen sonuçlar, gövde ve dal odununun hücresel yapısındaki farklılıkların odun işle- me ve kullanımında dikkate alınması gereken bir faktör olduğunu göstermektedir.

\section{KAYNAKLAR}

Anon., (2002). 1997 Köy Envanteri, T.C. Başbakanlık Devlet İstatistik Enstitüsü, Yayın No: 2618, S. 161, Ankara.

Ashori, A. (2006). Pulp And Paper From Kenaf Bast Fibers. Fibers Polym. J. 7(1): 26-29.

Berlyn, P.G., Miksche, J. (1976). Botanical Microtechnique and Cytochemystry, The lowa State University Press, Ames, lowa.

Bhat K.M., Bhat K.V., Dhamodaran T.K. (1985). Wood and Bark Properties of Branches of Selected Tree Species Growing in Kerala. KFRI Research Report 29. Kerala Forest Research Institute Peechi, Thrissur.

Bhat K.M., Bhat K.V., Dhamodaran T.K. (1989). Fibre Lenght Variation in Stem and Branches of Eleven tropical Hardwoods. IAWA Bull. n.s. 10 (1): 63-70.

Bozkurt, Y., Erdin, N. (1995). İğne Yapraklı ve Yapraklı Ağaç Odunlarında Tanım Özellikleri, İstanbul.

Carlquist, S. (1986). Terminology of Imperforate Tracheary Elements. IAWA Bulletin, N.S., Vol. (1): 75-81.

Çöpür, Y., Güler C., Akgül, M., Taşçıoğlu, C. (2007). Some Chemical Properties of Hazelnut Husk and Its Suitability for Particleboard Production. Build Environ 42(7): 25682572.

Dadzie, P. K., Amoah, M., Frimpong-Mensah, K., Shi, S. Q. (2016). Comparison of Density and Selected Microscopic Characteristics of Stem and Branch Wood of Two Commercial Trees in Ghana. Wood Science and Technology 50 (1): $91-104$.

Englerth, G. H. (1966). Framework of Qualitative Relationships in Wood Utilization, U.S.D.A. Forest Service Res. Paper FPL 45. 17 pp.

Gökmen, H. (1973). Kapalı Tohumlular Şark Matbaası, Ankara, I. Cilt. p. 186-190.

Gurau, L., Cionca, M., Mansfield-Williams, H., Sawyer, G., Zeleniuc, O. (2008). Comparison of the Mechanical Properties of Branch and Stem Wood for Three Species. Wood and Fiber Science 40(4): 647-656.

Gündüz, G., Yıldırım, N., Şirin, G., Onat, S. M. (2009). Ak Dut Ağacının Anatomik, Kimyasal, Fiziksel ve Mekanik Özellikleri. Düzce Üniversitesi Ormancllık Dergisi 5(1): 131149.

Haygreen J.G., Bowyer J.L. (1996). Wood Science and Forest Products - An Introduction (3rd ed.), lowa State University Press, Ames.

Hilton, M. (2001). Design for Sustainable Development: Success Factors, European Foundation for the Improvement of Living and Working Conditions, Office for Official Publications of the European Communities, Luxembourg,127 pp.

Karami, E., Pourtahmasi, K., Shahverdi, M. (2010). Wood Anatomical Structure of Morus alba L. and Morus nigra L., Native to Iran. Notulae Scientia Biologicae 2(4): 129-132.

Kurtoğlu, A. (1984). Ağaç Malzeme - Ağırlık Iliş̧ileri, İstanbul Üniversitesi Orman Fakültesi Dergisi, Seri B 34 (1): 150163.

Kurtoğlu, A. (1986). Kapı ve Pencere Endüstrisinde Kullanılan Ağaç Türleri, Istanbul Üniversitesi Orman Fakültesi Dergisi, Seri B 36 (4): 75-88. 
Machii, H., Koyama, H., Yamanouchi, K., Matsumoto, K., Kobayashi, S., Katagiri, K. (2001). A List of Morphological and Agronomical Traits of Mulberry Genetic Resources, Misc. Publ. Natl. Inst. Seric. Entomol. Sci., 29: 1-307.

Marcati, C. R., Longo, L. R., Wiedenhoeft , A., Barros, C. (2014). Comparative Wood Anatomy of Root and Stem of Citharexylum myrianthum (Verbenaceae). Rodriguésia 65(3):567-576.

McElwee, R. L., Tobias, R. C., Gregory, A. H. (1970). Wood Characteristics of Tree Southern Hardwood Species And Their Relationship To Pulping Properties, TAPPI 53 (10): 1882-1886.

Melo Júnior, J. C. F., Amorim, M. W., Soffiatti, P. (2018). Comperative Wood Anatomy of Ficus cestrifolia (Moraceae) in Two Distinct Soil Conditions. Rodriguésia 69 (4): 2109-2118.

Palhares, D., Paul, J. E., Alfredo, L., Pereira, L. A. R. (2007). Comparative Wood Anatomy of Stem, Root and Xylopodium of Brosimum Gaudichaudii (Moraceae). IAWA Journal 28 (1).

Phelps J.E., Isebrands J.G., Jowett D. (1982). Raw Material Quality of Short-term, Intensively Cultured Populus Clones. I. A Comparison of Stem and Branch Properties at Three Spacings. IAWA Bull. n.s. 3 (3-4): 193-200.

Ryu H. Y., Soh W.Y. (1988). Anatomical comparison of the secondary xylem in the branch, stem and root of Salix glandulosa and Quercus variabilis. J. Korean For. Soc. 77: 283-293.

Samariha, A., Kiaei, M., Talaeipour, M., Nemati, M. (2011). Anatomical Structural Differences Between Branch And Trunk İn Ailanthus altissima Wood, Indian Journal of Science and Technology, 4(12):1676-1678.

Stokke, D. D., Manwiller, F. G. (1994). Proportions of Wood Elements in Stem, Branch and Root Wood of Black Oak (Quercus velutina). IAWA Journal 15(3): 301-310.

Şanlı, İ (1977). Doğu Kayını (Fagus orientalis Lipsky.)'nın Türkiye'de Çeşitli Yörelerde Oluşan Odunları Üzerine Anatomik Araştırmalar. Matbaa Teknisyenleri Basımevi, İstanbul.

Vurdu, H. (1977). Anatomical Characteristics Of Stem, Branch And Root Wood In European Black Alder (Alnus glutinosa L. Gaertn.) Ph. D. Dissertation. Library, lowa State University of Science and Technology, Ames, lowa, USA.

Yaman, B. (2014). Anatomical Differences Between Stem and Branch Wood of Ficus carica subsp. carica, Modern Phytomorphology, 6: 79-83.

Yücel, E., Yaltırık, F., Öztürk, M. (1995). Süs Bitkileri (Ağaçlar ve Çalılar), Anadolu Üniversitesi, Fen Fakültesi, Yayın No:1, Eskişehir. 